\title{
Relationship between Blood Adipocytokines and Resting Energy Expenditure in Young and Elderly Women
}

\author{
Chiyoko UsUi ${ }^{1,2}$, Eri TAKAHASHI ${ }^{1}$, Yuko GANDO ${ }^{1}$, Kiyoshi SANADA ${ }^{3}$, Jun OKA ${ }^{4}$, \\ Motohiko MIYACHI ${ }^{5}$, Izumi TABATA ${ }^{5}$ and Mitsuru HiguCHI ${ }^{2,3, *}$ \\ ${ }^{1}$ Department of Sport Sciences, Graduate School of Human Sciences, Waseda University, 2-579-15 \\ Mikajima, Tokorozawa, Saitama 359-1192, Japan \\ ${ }^{2}$ Faculty of Sport Sciences, Waseda University, 2-579-15 Mikajima, Tokorozawa, Saitama \\ 359-1192, Japan \\ ${ }^{3}$ Consolidated Research Institute for Advanced Science and Medical Care, Waseda \\ University, 513, Wasedatsurumaki, Shinjuku-ku, Tokyo 162-0041, Japan \\ ${ }^{4}$ Department of Home Economics, Tokyo Kasei University, 1-18-1, Kaga, Itabashi-ku, \\ Tokyo 173-8602, Japan \\ ${ }^{5}$ Health Promotion and Exercise Program, National Institute of Health and Nutrition, \\ 1-23-1, Toyama, Shinjuku-ku, Tokyo 162-8636, Japan
}

(Received August 7, 2007)

\begin{abstract}
Summary It has been demonstrated in a previous study that resting energy expenditure (REE) is associated with adiponectin levels in the blood. However, body composition was not taken into consideration in that study. The purpose of the present study was to again investigate the relationship between blood adipocytokines and REE, adjusted by body composition, in both young and elderly women. REE and blood adipocytokines were measured in 115 young (age: $22.3 \pm 2.1$ y, BMI: $\left.21.3 \pm 1.9 \mathrm{~kg} / \mathrm{m}^{2}\right)$ and 71 elderly $(63.4 \pm 6.5 \mathrm{y}, 22.9 \pm$ $2.3 \mathrm{~kg} / \mathrm{m}^{2}$ ) women. Dual energy X-ray absorptiometry was used to measure percent body fat. Fat mass and fat free mass (FFM) were calculated. REE (kcal/d and $\mathrm{kcal} / \mathrm{kg} \mathrm{BW} / \mathrm{d}$ ) was lower in elderly women than in young women, but no significant difference was observed in REE, expressed as kcal/kg FFM/d, between the two groups. Although elderly women had a higher percent body fat and higher serum leptin concentrations than young women, plasma adiponectin concentrations did not differ between young and elderly women. In elderly women, REE (kcal/d) was significantly and inversely correlated with plasma adiponectin concentration $(r=-0.386, p<0.001)$, but REE expressed per kilogram of BW or FFM was not significantly correlated. Furthermore, no significant correlation was observed between REE ( $\mathrm{kcal} / \mathrm{d}$ ) and concentrations of plasma adiponectin or serum leptin, after adjusting for potential confounders such as body composition and hormones, in either age group. These results suggest that adipocytokines do not influence REE in adult women.
\end{abstract}

Key Words resting energy expenditure, adiponectin, leptin, age, female adults

Resting energy expenditure (REE) accounts for 60 to $80 \%$ of total daily energy expenditure and is the basis for estimating energy requirements. In the field of energy metabolism, early investigators showed intense interest in establishing the factors contributing to REE (1-3).

Recent progress has shown that adipocytokines, which are bioactive substances secreted from adipocytes $(4,5)$, play an important role in regulation of basal metabolic rate (6). In particular, much attention is paid to adiponectin, which is suggested to play a role in improving insulin resistance and protecting against arteriosclerosis (7-9). In addition, rodent studies suggest that energy expenditure is regulated by adiponec-

\footnotetext{
*To whom correspondence should be addressed at Faculty of Sport Sciences, Waseda University, 2-579-15 Mikajima, Saitama, 359-1192 Japan

E-mail:mhiguchi@waseda.jp
}

tin $(6,10-13)$. Further, Ruige et al. (14) recently demonstrated that a low resting metabolic rate (RMR; kcal/ d) is strongly and inversely associated with high adiponectin levels in overweight or obese humans. Together these studies suggest that there is a relationship between adiponectin and REE.

It is well known that body mass, especially fat free mass (FFM), is a useful parameter for estimating REE (15-17). Fat mass (FM) is also an important predictor of REE in elderly people even though it is low-metabolicrate tissue (17-21). However, in a previous study conducted to investigate the relationship between adiponectin and REE, body composition (FFM and FM) was not taken into consideration (14). It is therefore necessary to assess the effect of adiponectin on REE after adjusting for the confounding influence of body composition.

Therefore, we re-evaluated the relationship between blood adipocytokines and REE adjusted by body compo- 
sition in young and elderly women. We did not find any significant relationship between plasma adiponectin concentration and REE adjusted by body composition in either age group.

\section{MATERIALS AND METHODS}

Subjects. One hundred and fifteen young women $(22.3 \pm 2.1 \mathrm{y})$ and 71 elderly women $(63.4 \pm 6.5 \mathrm{y})$, who were at least $3 \mathrm{y}(13.5 \pm 7.5 \mathrm{y})$ post-menopause, were recruited for the study. Women who had BMI (kg/ $\mathrm{m}^{2}$ ) which fell outside the range $\mathrm{BMI}<18.5$, BMI $>30$ were excluded. There were 4 young and 17 elderly subjects who were overweight $(25 \leq \mathrm{BMI}<30)$. Included participants were not using any medications, including estrogen-replacement drugs. All subjects were informed of the purpose and possible risks of the study and then provided written informed consent, as approved by the Ethical Committee at the National Institute of Health and Nutrition in Japan.

Study protocol and indirect measurement of REE. Participants came to the National Institute of Health and Nutrition in the early morning. They were asked to minimize any walking prior to their laboratory visit for the REE measurement. REE was measured directly by open-circuit indirect calorimetry. Measurements were performed between 0700 and $0900 \mathrm{~h}$ in a room at constant temperature $\left(23-25^{\circ} \mathrm{C}\right)$. After entering the laboratory, subjects rested in the supine position for at least 30 min, and wore a Hans-Rudolph full face mask (Hans Rudolph Inc., Kansas City, MO, USA). Two samples of expired air were collected in Douglas bags over each of two $10 \mathrm{~min}$ periods, and the mean of the two values was used for analysis. For young subjects, all measurements were made during the follicular phase of the menstrual cycle.

An oxygen and carbon dioxide analyzer (Arco1000A, Arco System, Japan) was used to analyze the rate of oxygen consumption and carbon dioxide production. The volume of expired air was determined using a dry gas volume meter (DC-5, Shinagawa, Japan) and converted to standard temperature, pressure and dry gas (STPD). Gas exchange results were converted to REE (kcal/d) using Weir's equation (22).

Body composition analysis. Body weight (BW) was measured to the nearest $0.1 \mathrm{~kg}$ using an electronic scale (Inner Scan BC-600, TANITA Co., Japan), and height (Ht) was measured to the nearest $0.1 \mathrm{~cm}$ using a stadiometer (YL-65, YAGAMI Inc., Japan). Body mass index (BMI) was calculated by dividing BW in kilograms by the $\mathrm{Ht}$ in meters squared $\left(\mathrm{kg} / \mathrm{m}^{2}\right)$. The percentage of whole body fat (\% body fat) was measured using dual energy X-ray absorptiometry (Hologic QDR-4500 DXA Scanner, Hologic Inc., Waltham, MA, USA). Manufacturer's software version 11.2 for Windows was used to analyze the \% body fat. FFM and FM were calculated by BW and \% body fat.

Blood samples. Venous blood samples (fasting for at least $12 \mathrm{~h}$ ) were collected for measurements of serum glucose, glycosylated hemoglobin $\left(\mathrm{Hb}_{1 \mathrm{c}}\right)$, total cholesterol, HDL-cholesterol, triglycerides, estradiol $\left(\mathrm{E}_{2}\right)$, total triiodothyronine $\left(\mathrm{T}_{3}\right)$, leptin, and plasma adiponectin. Serum and plasma samples were stored at $-80^{\circ} \mathrm{C}$ for subsequent analysis. All blood parameters were analyzed by SRL, Inc. (Tokyo, Japan) and Mitsubishi Chemical Medience Corporation (Tokyo, Japan).

Statistical analysis. The data were presented as mean \pm standard deviation (SD). Statistical analyses were carried out with the Sigma Stat 2.03 (Systat Software Inc., California, USA). Statistical analysis was performed using the Student's $t$-test for parametric variables and the Mann-Whitney rank sum test for nonparametric variables to determine differences between young and elderly women. To determine the associations between REE and adipocytokines, partial correlation coefficients were used after adjusting for the potential confounding influence of FM $(\mathrm{kg}), \mathrm{FFM}(\mathrm{kg}), \mathrm{E}_{2}(\mathrm{pg} /$ $\mathrm{mL})$, and $\mathrm{T}_{3}(\mathrm{ng} / \mathrm{dL})$. For all the statistical analyses, the level of significance was defined as a $p$ value of less than 0.05 .

\section{RESULTS}

Table 1 presents comparisons of characteristics, whole body composition, and blood biochemical profiles. Ht was significantly lower in the elderly women than in young women. However, no significant difference in BW was noted between the two groups. The elderly women had significantly higher levels of \% body fat and FM, and lower levels of FFM than the young group.

$\mathrm{REE}$ ( $\mathrm{kcal} / \mathrm{d}$ and $\mathrm{kcal} / \mathrm{kg} \mathrm{BW} / \mathrm{d}$ ) in the elderly group was significantly lower than in the young group (Table 2). When REE is expressed in terms of $\mathrm{kcal} / \mathrm{kg} \mathrm{FFM} / \mathrm{d}$, however, no significant difference in REE was found between the two groups. No significant difference in plasma adiponectin concentration was noted between the two groups, whereas serum leptin concentration was significantly higher in elderly women than in young women.

There was no significant relationship observed between REE (kcal/d, kcal/kg BW/d and kcal/kg FFM/d) and plasma adiponectin concentration in young women (Fig. 1, a-1-a-3). In contrast, in elderly women, REE (kcal/d) was significantly and inversely correlated with plasma adiponectin concentration $(r=-0.386$, $p<0.001$, Fig. 1, b-1), but REE expressed per kilogram BW and FFM were not significantly correlated (Fig. 1, b2, b-3). Significant and inverse relationships between REE adjusted by BW and concentrations of serum leptin were observed in the two groups (young: $r=-0.318$, elderly: $r=-0.426, p<0.001$, respectively, Fig. 2, a-2, b-2). When REE was expressed relative to FFM, however, no significant relationships were obtained for either group (Fig. 2, a-3, b-3).

A partial correlation coefficient calculated after adjusting for the confounding influence of FM (kg), FFM $(\mathrm{kg}), \mathrm{E}_{2}(\mathrm{pg} / \mathrm{mL})$, and $\mathrm{T}_{3}(\mathrm{ng} / \mathrm{dL})$ did not demonstrate any significant relationship between REE and concentrations of plasma adiponectin and serum leptin (Table $3)$. 
Table 1. Physical and biochemical characteristics in young and elderly women.

\begin{tabular}{|c|c|c|c|c|}
\hline & $\begin{array}{l}\text { Young } \\
(n=115)\end{array}$ & & $\begin{array}{l}\text { Elderly } \\
(n=71)\end{array}$ & \\
\hline Age (y) & $22.3 \pm 2.1$ & $(19.1-29.5)$ & $63.4 \pm 6.5^{\dagger}$ & $(50.2-77.0)$ \\
\hline $\mathrm{Ht}(\mathrm{cm})$ & $161.3 \pm 6.7$ & $(142.2-181.0)$ & $153.8 \pm 5.2^{*}$ & $(141.3-164.7)$ \\
\hline BW (kg) & $55.4 \pm 6.5$ & $(41.7-73.7)$ & $54.2 \pm 6.0$ & $(41.4-72.2)$ \\
\hline BMI $\left(\mathrm{kg} / \mathrm{m}^{2}\right)$ & $21.3 \pm 1.9$ & $(18.5-26.6)$ & $22.9 \pm 2.3^{*}$ & $(19.4-28.9)$ \\
\hline$\%$ body fat & $24.0 \pm 4.4$ & $(14.3-35.7)$ & $30.2 \pm 4.8^{*}$ & $(18.6-38.9)$ \\
\hline $\mathrm{FM}(\mathrm{kg})$ & $13.3 \pm 3.0$ & $(7.5-24.8)$ & $16.5 \pm 4.0^{*}$ & $(8.2-26.7)$ \\
\hline FFM (kg) & $42.1 \pm 5.5$ & $(31.4-57.5)$ & $37.7 \pm 3.5^{\dagger}$ & $(28.2-38.9)$ \\
\hline Glucose (mg/dL) & $87 \pm 5$ & $(69-100)$ & $94 \pm 8^{\dagger}$ & $(78-115)$ \\
\hline $\mathrm{HbA}_{1 \mathrm{c}}(\%)$ & $4.8 \pm 0.3$ & $(3.9-5.7)$ & $5.1 \pm 0.3^{\dagger}$ & $(4.6-6.0)$ \\
\hline Total cholesterol (mg/dL) & $178 \pm 26$ & $(121-249)$ & $216 \pm 27^{*}$ & $(158-282)$ \\
\hline HDL-cholesterol (mg/dL) & $69 \pm 13$ & $(40-100)$ & $66 \pm 15$ & $(34-107)$ \\
\hline Triglycerides (mg/dL) & $60 \pm 24$ & $(25-182)$ & $93 \pm 44^{\dagger}$ & $(34-280)$ \\
\hline $\mathrm{E}_{2}(\mathrm{pg} / \mathrm{mL})$ & $75 \pm 60$ & $(10-295)$ & $11 \pm 3^{\dagger}$ & $(10-29)$ \\
\hline $\mathrm{T}_{3}(\mathrm{ng} / \mathrm{dL})$ & $108 \pm 16$ & $(61-150)$ & $112 \pm 18$ & $(80-160)$ \\
\hline
\end{tabular}

Values are means \pm SD (range; minimum-maximum), Ht: height, BW: body weight, BMI: body mass index, FM: fat mass, FFM: fat free mass, $\mathrm{HbA}_{1 c}$ : glycosylated hemoglobin, $\mathrm{E}_{2}$ : estradiol, $\mathrm{T}_{3}$ : total triiodothyronine, ${ }^{*} p<0.001$ vs. young group (Student's $t$-test), ${ }^{\dagger} p<0.001$ vs. young group (Mann-Whitney rank sum test).

Table 2. Resting energy expenditure and adipocytokines in young and elderly women.

\begin{tabular}{ccccc}
\hline & $\begin{array}{c}\text { Young } \\
(n=115)\end{array}$ & & $\begin{array}{c}\text { Elderly } \\
(n=71)\end{array}$ \\
\hline $\mathrm{REE}(\mathrm{kcal} / \mathrm{d})$ & $1,190 \pm 154$ & $(830-1,622)$ & $1,085 \pm 109^{\dagger}$ & $(913-1,459)$ \\
$(\mathrm{kcal} / \mathrm{kg} \mathrm{BW} / \mathrm{d})$ & $21.5 \pm 1.9$ & $(17.8-27.5)$ & $20.1 \pm 1.9^{*}$ & $(16.2-25.1)$ \\
$(\mathrm{kcal} / \mathrm{kg} \mathrm{FFM} / \mathrm{d})$ & $28.4 \pm 2.3$ & $(24.0-33.7)$ & $28.9 \pm 2.4$ & $(23.5-35.7)$ \\
Adiponectin $(\mu \mathrm{g} / \mathrm{mL})$ & $9.9 \pm 3.8$ & $(2.9-22.1)$ & $9.9 \pm 4.1$ & $(2.6-20.8)$ \\
Leptin $(\mathrm{ng} / \mathrm{mL})$ & $6.1 \pm 3.1$ & $(1.1-19.8)$ & $7.8 \pm 4.4^{\dagger \dagger}$ & $(1.5-25.7)$ \\
\hline
\end{tabular}

Values are means \pm SD (range; minimum-maximum), REE: resting energy expenditure, ${ }^{*} p<0.001$ vs. young group (Student's $t$-test), ${ }^{\dagger} p<0.001$ and ${ }^{\dagger \dagger} p<0.05$ vs. young group (Mann-Whitney rank sum test).

\section{DISCUSSION}

The present study demonstrates that plasma adiponectin and serum leptin concentrations are not associated with REE in either young or elderly women when confounding factors, such as FM and FFM, are taken into account.

Elderly women recruited in this study were at least 3 y post-menopause. Although no significant difference in BW was noted between the young and elderly women, the elderly women had significantly higher levels of \% body fat and FM, and lower levels of FFM than the young group (Table 1). These results are consistent with previous studies, the results of which indicated that adipose tissue mass is controlled by steroid hormones and that menopause is also associated with increased body mass accompanied by elevated adiposity in females $(23,24)$.

In the present cross-sectional study, REE ( $\mathrm{kcal} / \mathrm{d}$ and $\mathrm{kcal} / \mathrm{kg} \mathrm{BW} / \mathrm{d}$ ) in the elderly group was significantly lower than in the young group. However, when REE was expressed per kilogram of FFM, no significant difference was observed between the two groups (Table 2).
This evidence suggests that the specific metabolic rate per FFM does not decline with advancing age, and that REE is regulated mainly by the mass of the tissueorgans with both lower and higher metabolic rates, including skeletal muscle, intestinal organs and residuals in adults $(25-28)$.

It is generally well known that thyroid function is associated with REE (29). In addition, previous studies in premenopausal women $(30,31)$ have shown that REE is lower during the early follicular phase of menstrual cycle, when $\mathrm{E}_{2}$ is low, than in the midluteal phase. The present investigation demonstrated a significant relationship between serum $\mathrm{T}_{3}$ concentration and REE in terms of $\mathrm{kcal} / \mathrm{kg} \mathrm{FFM} / \mathrm{d}$ in all subjects (young: $r=0.493$, elderly: $r=0.385$, all subjects: $r=0.456$, $p<0.001$, respectively). In the young group but not the elderly group, serum $\mathrm{E}_{2}$ concentration significantly correlated with REE (kcal/kg FFM/d), which was measured during the follicular phase of the menstrual cycle $(r=$ $0.222, p<0.05)$. These results suggest that concentrations of serum $\mathrm{T}_{3}$ and $\mathrm{E}_{2}$ may have a role in the regulation of REE in adult women.

Previous animal studies demonstrated that adiponec- 
Young
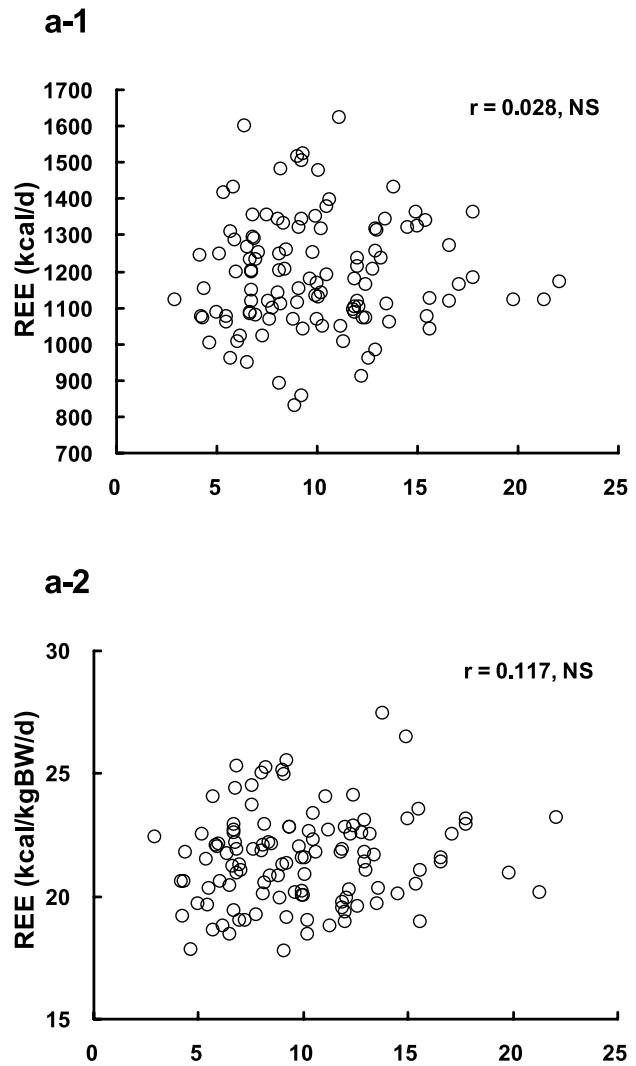

a-3

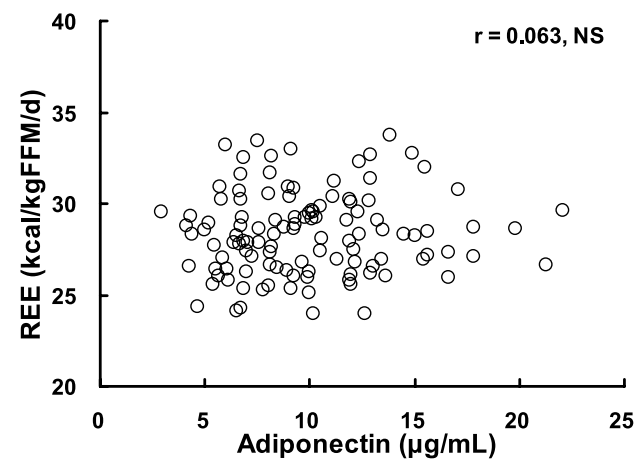

Elderly

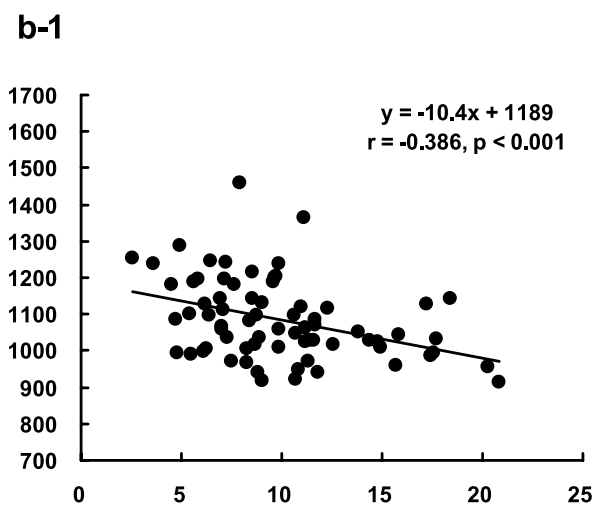

b-2

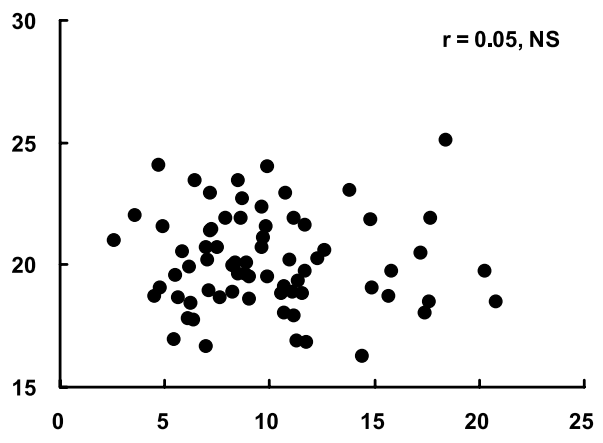

b-3

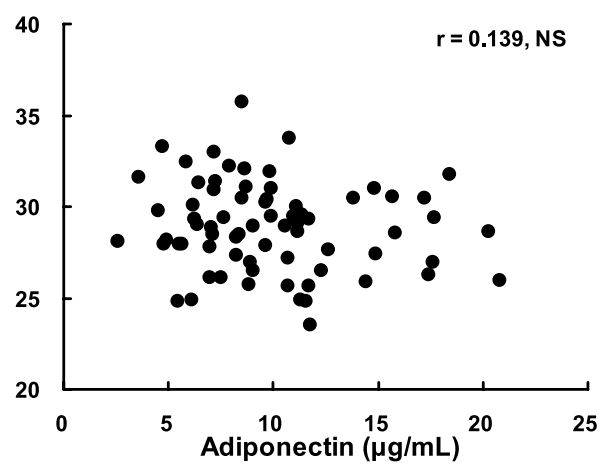

Fig. 1. Relationship between REE (kcal/d, kcal/kg BW/d, kcal/kg FFM/d) and adiponectin.

tin increases $\beta$-oxidation through AMP-kinase activation, suggesting that adiponectin plays crucial and central roles in the regulation of energy expenditure (32). In contrast, we demonstrate that a significant inverse link exists between plasma adiponectin concentrations and REE in elderly women $(r=-0.386, p<0.001$, Fig. $1, b-1)$. This is consistent with the results observed in overweight and obese males and females (14). These results might provide the possibility that protection by adiponectin against obesity-related disorders is especially important for human subjects with low RMR, and it is tempting to suggest plasma adiponectin as a valuable predictor for RMR, or vice versa.

We previously demonstrated that both FFM and FM are important predictors of REE in elderly people $(20$, 21). Thus, the inverse association between REE (kcal/d) and concentrations of plasma adiponectin in the present investigation in the elderly group may reflect spurious correlations. Therefore, for the purpose of determining the precise relationship between plasma adiponectin concentrations and REE, we adopted a partial correlation coefficient after adjusting for confounding influences of FM (kg), FFM (kg), $\mathrm{E}_{2}(\mathrm{pg} / \mathrm{mL})$, and $\mathrm{T}_{3}$ (ng/dL). As a consequence, we have demonstrated that REE is not significantly correlated with plasma adiponectin concentrations (Table 3 ). These results suggest that adiponectin is not involved in the regulation of REE in young or elderly women.

Jørgensen et al. (33) demonstrated that serum leptin was a strong positive determinant for RMR in men. However, in their study, no adequate adjustment of RMR was made for either FFM or FM. In the present 
Young

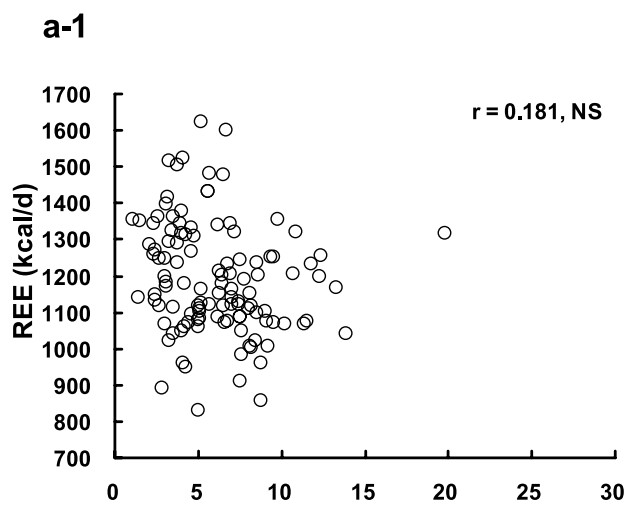

a-2

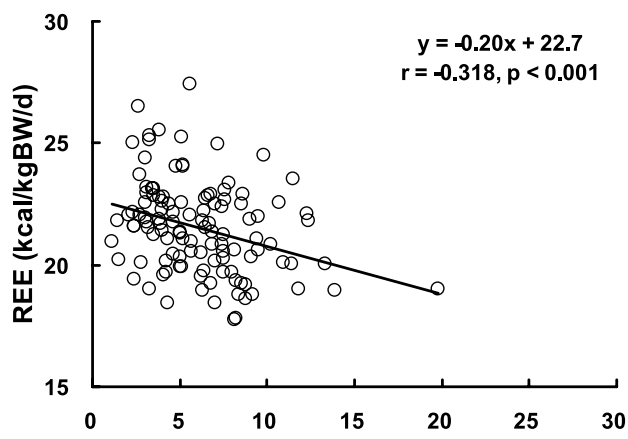

a-3

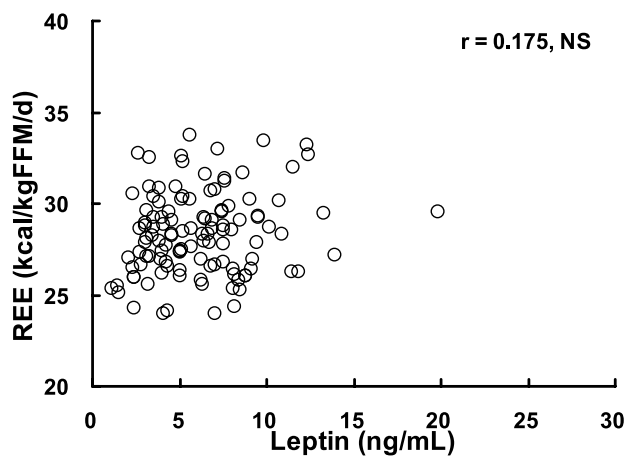

Elderly

\section{b-1}

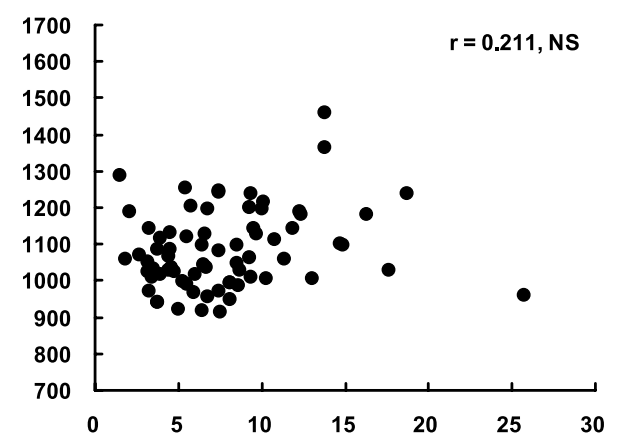

b-2

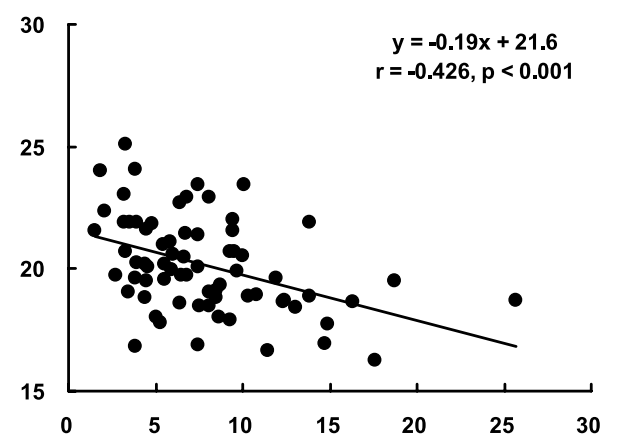

b-3

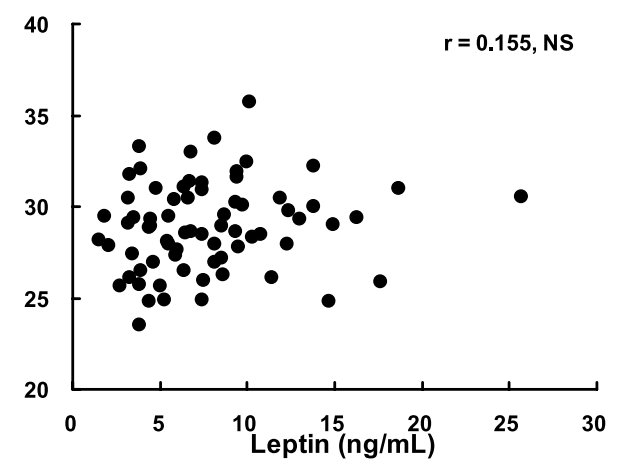

Fig. 2. Relationship between REE (kcal/d, kcal/kg BW/d, kcal/kg FFM/d) and leptin.

Table 3. Partial correlation coefficient to REE in female subjects.

\begin{tabular}{lrrrr}
\hline & \multicolumn{2}{c}{$\begin{array}{c}\text { Young } \\
(n=115)\end{array}$} & \multicolumn{2}{c}{$\begin{array}{c}\text { Elderly } \\
(n=71)\end{array}$} \\
\cline { 2 - 5 } \multicolumn{1}{c}{ Variable } & \multicolumn{1}{c}{$\beta$} & $p$ & $\beta$ & $p$ \\
\hline REE $(\mathrm{kcal} / \mathrm{d})$ & & & & \\
Adiponectin $(\mu \mathrm{g} / \mathrm{mL})$ & 0.138 & 0.148 & -0.200 & 0.104 \\
Leptin $(\mathrm{ng} / \mathrm{mL})$ & -0.006 & 0.947 & 0.067 & 0.588 \\
\hline
\end{tabular}

$\beta$ : partial correlation coefficient: controlling for FM $(\mathrm{kg})$, FFM (kg), $E_{2}(\mathrm{pg} / \mathrm{mL})$, and $\mathrm{T}_{3}(\mathrm{ng} / \mathrm{dL})$. investigation, no significant relationship between leptin and REE adjusted by body composition was observed (Table 3). This result is consistent with the report of Neuhäuser-Berthold et al. (34), suggesting that leptin might not have a significant role in the regulation of REE.

Our investigation has a few limitations. First, we did not test middle-aged (30-49 y) adults. Second, we did not include male subjects. Third, although adipocytokines such as adiponectin and leptin were related to the levels of body fat mass, we did not observe for lean and obese subjects. Future studies are needed to investigate this association in lean and obese adults and middleaged adults.

In conclusion, the present investigation provides evi- 
dence to suggest that adipocytokines, such as adiponectin and leptin, do not influence REE in adult women.

\section{Acknowledgments}

The authors would like to express their appreciation to the subjects for their participation in this study. We wish to thank the members of the National Institute of Health and Nutrition for their help in this experiment. This work was supported by a Research Grant for Academic Frontier Projects from the Ministry of Education, Culture, Sports, Science and Technology (05F-02), a Waseda University Grant for Special Research Projects (2005A-932, 2006B-242), Health Sciences Research Grants from the Ministry of Health, Labor and Welfare, Medical Health Care Research Grants from the Consolidated Research Institute for Advanced Science and Medical Care at Waseda University, Research Grants from the Japanese Olympic Committee, and a Research Grant from Kao Research Council for the Study of Healthcare Science.

\section{REFERENCES}

1) Cunningham JJ. 1980. A reanalysis of the factors influencing basal metabolic rate in normal adults. Am J Clin Nutr 33: 2372-2374.

2) Cunningham JJ. 1991. Body composition as a determinant of energy expenditure: a synthetic review and a proposed general prediction equation. Am J Clin Nutr 54: 963-969.

3) Nelson KM, Weinsier RL, Long CL, Schutz Y. 1992. Prediction of resting energy expenditure from fat-free mass and fat mass. Am J Clin Nutr 56: 848-856.

4) Maeda K, Okubo K, Shimomura I, Mizuno K, Matsuzawa Y, Matsubara K. 1997. Analysis of an expression profile of genes in the human adipose tissue. Gene 190: 227-235.

5) Shimomura I, Funahashi T, Takahashi M, Maeda K, Kotani K, Nakamura T, Yamashita S, Miura M, Fukuda Y, Takemura K, Tokunaga K, Matsuzawa Y. 1996. Enhanced expression of PAI-1 in visceral fat: possible contributor to vascular disease in obesity. Nat Med $\mathbf{2}$ : 800-803.

6) Yoda M, Nakano Y, Tobe T, Shioda S, Choi-Miura NH, Tomita M. 2001. Characterization of mouse GBP28 and its induction by exposure to cold. Int J Obes Relat Metab Disord 25: 75-83.

7) Havel PJ. 2004. Update on adipocyte hormones: regulation of energy balance and carbohydrate/lipid metabolism. Diabetes 53: S143-S151.

8) Matsuzawa Y, Funahashi T, Kihara S, Shimomura I. 2004. Adiponectin and metabolic syndrome. Arterioscler Thromb Vasc Biol 24: 29-33.

9) Maeda K. 2006. Adiponectin. Rinsyo Eiyo 108: 684689 (in Japanese).

10) Swan H, Schatte C. 1977. Antimetabolic extract from the brain of the hibernating ground squirrel Citellus tridecemlineatus. Science 195: 84-85.

11) Kondo N, Kondo J. 1992. Identification of novel blood proteins specific for mammalian hibernation. J Biol Chem 267: 473-478.

12) Takamatsu N, Ohba K, Kondo J, Kondo N, Shiba T. 1993. Hibernation-associated gene regulation of plasma proteins with a collagen-like domain in mammalian hibernators. Mol Cell Biol 13: 1516-1521.

13) Horton ND, Kaftani DJ, Bruce DS, Bailey EC, Krober AS, Jones JR, Turker M, Khattar N, Su TP, Bolling SF, Oeltgen PR. 1998. Isolation and partial characterization of an opioid-like $88 \mathrm{kDa}$ hibernation-related protein. Comp Biochem Physiol B Biochem Mol Biol 119: 787-805.

14) Ruige JB, Ballaux DP, Funahashi T, Mertens IL, Matsuzawa Y, Van Gaal LF. 2005. Resting metabolic rate is an important predictor of serum adiponectin concentrations: potential implications for obesity-related disorders. Am J Clin Nutr 82: 21-25.

15) Fukagawa NK, Bandini LG, Young JB. 1990. Effect of age on body composition and resting metabolic rate. Am J Physiol 259: E233-E238.

16) Ravussin E, Bogardus C. 1989. Relationship of genetics, age, and physical fitness to daily energy expenditure and fuel utilization. Am J Clin Nutr 49: 968-975.

17) Tataranni PA, Ravussin E. 1995. Variability in metabolic rate: biological sites of regulation. Int J Obes Relat Metab Disord 19: S102-S106.

18) Astrup A, Buemann B, Christensen NJ, Madsen J, Gluud C, Bennett P, Svenstrup B. 1992. The contribution of body composition, substrates, and hormones to the variability in energy expenditure and substrate utilization in premenopausal women. J Clin Endocrinol Metab 74: $279-286$.

19) Svendsen OL, Hassager C, Christiansen C. 1993. Impact of regional and total body composition and hormones on resting energy expenditure in overweight postmenopausal women. Metabolism 42: 1588-1591.

20) Usui C, Oka J, Yamakawa J, Sasaki Y, Higuchi M. 2003. Basal metabolic rate and its determinants in postmenopausal women. Jpn J Phys Fitness Sports Med 52: 189198 (in Japanese).

21) Usui C, Kaneko K, Oka J, Tabata I, Higuchi M. 2005. Basal metabolic rate and its determinants in older males and females. Jpn J Nutr Diet 63: 21-25 (in Japanese).

22) Weir JB. 1949. New methods for calculating metabolic rate with special reference to protein metabolism. J Physiol 109: 1-9.

23) Wade GN, Gray JM. 1979. Gonadal effects on food intake and adiposity: a metabolic hypothesis. Physiol Behav 22: 583-593.

24) Svendsen OL, Hassager C, Christiansen C. 1995. Ageand menopause-associated variations in body composition and fat distribution in healthy women as measured by dual-energy X-ray absorptiometry. Metabolism 44: 369-373.

25) Gallagher D, Belmonte D, Deurenberg P, Wang Z, Krasnow N, Pi-Sunyer FX, Heymsfield SB. 1998. Organ-tissue mass measurement allows modeling of REE and metabolically active tissue mass. Am J Physiol 275: E249-E258.

26) Hayes M, Chustek M, Wang Z, Gallagher D, Heshka S, Spungen A, Bauman W, Heymsfield SB. 2002. DXA: potential for creating a metabolic map of organ-tissue resting energy expenditure components. Obes Res 10: 969-977.

27) Illner K, Brinkmann G, Heller M, Bosy-Westphal A, Müller MJ. 2000. Metabolically active components of fat free mass and resting energy expenditure in nonobese adults. Am J Physiol Endocrinol Metab 278: E308-E315.

28) Midorikawa T, Kondo M, Beekley MD, Koizumi K, Abe T. 2007. High REE in Sumo wrestlers attributed to large organ-tissue mass. Med Sci Sports Exerc 39: 688-693. 
29) Danforth E Jr, Burger A. 1984. The role of thyroid hormones in the control of energy expenditure. Clin Endocrinol Metab 13: 581-595.

30) Solomon SJ, Kurzer MS, Calloway DH. 1982. Menstrual cycle and basal metabolic rate in women. Am J Clin Nutr 36: 611-616.

31) Bisdee JT, James WP, Shaw MA. 1989. Changes in energy expenditure during the menstrual cycle. $\mathrm{Br} J$ Nutr 61: 187-199.

32) Yamauchi T, Kamon J, Minokoshi Y, Ito Y, Waki H, Uchida S, Yamashita S, Noda M, Kita S, Ueki K, Eto K, Akanuma Y, Froguel P, Foufelle F, Ferre P, Carling D, Kimura S, Nagai R, Kahn BB, Kadowaki T. 2002. Adi- ponectin stimulates glucose utilization and fatty-acid oxidation by activating AMP-activated protein kinase. Nat Med 8: 1288-1295.

33) Jørgensen JO, Vahl N, Dall R, Christiansen JS. 1998. Resting metabolic rate in healthy adults: relation to growth hormone status and leptin levels. Metabolism 47: 1134-1139.

34) Neuhäuser-Berthold M, Herbert BM, Lührmann PM, Sültemeier AA, Blum WF, Frey J, Hebebrand J. 2000. Resting metabolic rate, body composition, and serum leptin concentrations in a free-living elderly population. Eur J Endocrinol 142: 486-492. 